\title{
Transcriptional regulation of the novobiocin biosynthetic gene cluster
}

\section{Correspondence \\ Lutz Heide \\ heide@uni-tuebingen.de}

Received 12 July 2009

Revised 10 September 2009

Accepted 10 September 2009

\section{Volker Dangel, ${ }^{1}$ Johannes Härle, ${ }^{1} \dagger$ Christiane Goerke, ${ }^{2}$ Christiane Wolz, ${ }^{2}$ Bertolt Gust, ${ }^{1}$ Jean-Luc Pernodet ${ }^{3}$ and Lutz Heide ${ }^{1}$}

\author{
${ }^{1}$ Pharmaceutical Biology, Pharmaceutical Institute, Eberhard-Karls-Universität Tübingen, Auf der \\ Morgenstelle 8, 72076 Tübingen, Germany \\ ${ }^{2}$ Institute for Medical Microbiology and Hygiene, Universitätsklinikum Tübingen, Elfriede-Aulhorn- \\ Strasse 6, 72076 Tübingen, Germany \\ ${ }^{3}$ Univ. Paris-Sud 11, CNRS, UMR 8621, Institut de Génétique et Microbiologie, 91405 Orsay \\ Cedex, France
}

The aminocoumarin antibiotic novobiocin is a gyrase inhibitor formed by a Streptomyces strain. The biosynthetic gene cluster of novobiocin spans $23.4 \mathrm{~kb}$ and contains 20 coding sequences, among them the two regulatory genes novE and novG. We investigated the location of transcriptional promoters within this cluster by insertion of transcriptional terminator cassettes and RT-PCR analysis of the resulting mutants. The cluster was found to contain eight DNA regions with promoter activity. The regulatory protein NovG binds to a previously identified binding site within the promoter region located upstream of novH, but apparently not to any of the other seven promoters. Quantitative real-time PCR was used to compare the number of transcripts in a strain carrying an intact novobiocin cluster with strains carrying mutated clusters. Both in-frame deletion of the regulatory gene novG and insertion of a terminator cassette into the biosynthetic gene novH led to a strong reduction of the number of transcripts of the genes located between novH and novW. This suggested that these 16 biosynthetic genes form a single operon. Three internal promoters are located within this operon but appear to be of minor importance, if any, under our experimental conditions. Transcription of novG was found to depend on the presence of NovE, suggesting that the two regulatory genes, novE and novG, act in a cascade-like mechanism. The resistance gene $g y r B^{R}$, encoding an aminocoumarin-resistant gyrase $B$ subunit, may initially be co-transcribed with the genes from novH to novW. However, when the gyrase inhibitor novobiocin accumulates in the cultures, $g y r B^{R}$ is transcribed from its own promoter. Previous work has suggested that this promoter is controlled by the superhelical density of chromosomal DNA.

\section{INTRODUCTION}

Genome mining, i.e. the sequencing of bacterial genomes in search of novel biosynthetic gene clusters, is a promising new strategy for the discovery of bioactive substances, most importantly antibiotics (Wilkinson \& Micklefield, 2007; Zerikly \& Challis, 2009). The principal bottleneck for the

tPresent address: Pharmaceutical Biology and Biotechnology, AlbertLudwigs-Universität Freiburg, Stefan-Meier-Straße 19, 79104 Freiburg, Germany.

Abbreviations: EMSA, electrophoretic mobility shift assay; 4HPP, 4hydroxyphenylpyruvate; qRT-PCR, quantitative RT-PCR.

A set of supplementary methods, describing electrophoretic mobility shift assays, a supplementary figure, showing quantitative real-time analysis of Streptomyces coelicolor strains, and two supplementary tables, listing bacterial strains, plasmids and cosmids used in this study, and primers used in this study, with references, are available with the online version of this paper. success of this strategy is the step from sequence data, which can be readily obtained by highly automated procedures, to the production of the encoded secondary metabolites in sufficient quantities for pharmacological screening. This can be achieved, e.g. by heterologous expression of the gene clusters. For this purpose, an understanding of the regulation of the expression of bacterial secondary metabolic gene clusters is of great practical importance for future drug discovery.

The aminocoumarin antibiotic novobiocin is produced by Streptomyces caeruleus (syn. Streptomyces spheroides) and is a potent inhibitor of bacterial gyrase (Maxwell \& Lawson, 2003). It has been licensed for the treatment of infections with Gram-positive pathogens in humans (Albamycin, Pfizer). The closely related aminocoumarins clorobiocin and coumermycin $\mathrm{A}_{1}$, produced by different Streptomyces strains, are even more potent antibacterials (Maxwell \& 
Lawson, 2003). The biosynthetic gene clusters of all three antibiotics have been cloned and sequenced from the genuine producer strains, and their heterologous expression in Streptomyces coelicolor M512 has provided the basis for the generation of many new aminocoumarins by mutasynthesis and pathway engineering experiments (Heide et al., 2008; Li \& Heide, 2005).

The novobiocin biosynthetic gene cluster spans $23.4 \mathrm{~kb}$ and consists of 20 coding sequences. The functions of these genes have been elucidated (Fig. 1) (Li \& Heide, 2004, 2006). novHIJ and $K$ are responsible for the synthesis of the aminocoumarin moiety. nov $Q$ and $R$ are responsible for the generation of the prenylated 4-hydroxybenzoyl moiety, and novSTUV and $W$ for the generation of the deoxysugar. The gene products of novL and novM catalyse the linkage of these three moieties. nov $\mathrm{N}$, novO and novP encode enzymes which catalyse tailoring reactions, i.e. the carbamoylation and methylation of the novobiocin skeleton. novF is probably responsible for the supply of 4-hydroxyphenylpyruvate (4HPP), a precursor of both aromatic moieties of novobiocin. gyrB $B^{R}$ encodes a resistance gene.

The coding sequences for nov $Q$, novR and novS overlap, suggesting a translational coupling of these genes (Fig. 2k). The same is true for novV and novW, as well as for novJ and novK. The genes novHIJ, as well as novKLM, are separated by very short intergenic regions ( $\leqslant 19 \mathrm{bp}$ ). Large intergenic regions, suggestive of the presence of promoters, are found upstream of novE (180 bp intergenic region), novG (105 bp), novH (195 bp), novO (230 bp) and gyrB (376 bp) (Fig. 2k). The promoter activities of the DNA regions upstream of $g y r B^{R}$ and upstream of novE have been shown by Thiara \& Cundliffe (1989) and by Dangel et al. (2008), respectively. Eustáquio et al. (2005b) investigated the promoter situated upstream of novH, which contains the binding site for the positive regulator protein NovG. No NovG binding site is present in the large intergenic region upstream of novO (Eustáquio et al., 2005b). In this study, we carried out additional electrophoretic mobility shift assays (EMSAs) with NovE (data not shown), but also failed to show binding to the region upstream of novO.

Notably, all 20 genes of the novobiocin biosynthetic gene cluster are arranged in the same orientation and many, or even all, of them could therefore be transcribed as a single operon. Bioinformatic sequence analysis shows no rhoindependent terminators within the entire cluster.

The gene clusters of novobiocin, clorobiocin and coumermycin $A_{1}$ each contain a certain regulatory gene, termed nov $G$, cloG or $\operatorname{cou} G$, respectively, which show sequence similarity to $s t r R$, a positive regulator of streptomycin biosynthesis (Tomono et al., 2005). EMSAs have shown that NovG binds to a well-conserved inverted repeat located in the intergenic region between nov $G$ and novH (Eustáquio et al., 2005b). This sequence is similar to the StrR binding sites in the streptomycin cluster, and to the binding sites of the closely related Bbr in the balhimycin cluster (Shawky et al., 2007). These data suggest that NovG and its orthologues CloG and CouG act as positive regulators of the transcription of the genes located downstream of their respective binding sites, although direct experimental proof of this hypothesis has not been provided so far.

Besides nov $G$, the novobiocin gene cluster contains only one additional putative regulatory gene, i.e. novE. Orthologues of $n o v E$ are found in the biosynthetic gene clusters of clorobiocin, coumermycin $\mathrm{A}_{1}$, rubradirin and lincomycin (cloE, couE, rubC4 and $l m b U$, respectively), but their function is as yet unknown. Inactivation of novE in a heterologously expressed novobiocin cluster leads to a strong reduction of novobiocin formation, and overexpression of novE leads to a twofold increase in production. Notably, inactivation of novE can be complemented by overexpression of novG (Dangel et al., 2008). This suggests a role for $n o v E$ as a positive regulator of novobiocin biosynthesis, although its influence on transcription of biosynthetic genes has not been demonstrated so far. No DNA binding activity of the NovE protein to the DNA region upstream of novG has been found in EMSAs (Dangel et al., 2008).

In the present study, we investigated the transcriptional regulation of the novobiocin biosynthetic gene cluster. We present evidence that novE and novG act as transcriptional activators of novobiocin biosynthetic genes and that these two regulators act in a cascade-like mechanism.

\section{METHODS}

Bacterial strains, plasmids, cosmids and culture conditions. Supplementary Table S1 shows the bacterial strains, plasmids and cosmids used in this study. The REDIRECT technology kit for PCR targeting (Gust et al., 2003) was obtained from Plant Bioscience Limited.

Escherichia coli strains were cultivated in Luria-Bertani (LB) medium (Sambrook \& Russell, 2001). S. coelicolor strains were routinely cultured in $300 \mathrm{ml}$ baffled Erlenmeyer flasks containing a stainless steel spring and $50 \mathrm{ml}$ yeast malt extract glucose (YMG) medium [1\% $(\mathrm{w} / \mathrm{v})$ malt extract, $0.4 \%(\mathrm{w} / \mathrm{v})$ yeast extract and $0.4 \%(\mathrm{w} / \mathrm{v})$ glucose ( $\mathrm{pH}$ 7.3)]. Cultivation was carried out at $30{ }^{\circ} \mathrm{C}$ and 200 r.p.m. for 2 days. For preparation of protoplasts or isolation of genomic DNA, strains were grown in tryptone soya broth (TSB) medium (Kieser et al., 2000).

For analysis of secondary metabolite production and RT-PCR experiments, $1 \mathrm{ml}$ YMG preculture was inoculated into $300 \mathrm{ml}$ baffled flasks containing $50 \mathrm{ml}$ chemically defined minimal (CDM) production medium (Kominek, 1972), and cells were cultivated at $30{ }^{\circ} \mathrm{C}$ and 200 r.p.m.

For quantitative RT-PCR (qRT-PCR) experiments, strains were cultivated in 24-square deepwell plates (Duetz et al., 2000). A $50 \mathrm{ml}$ volume of YMG preculture, prepared as described above, was centrifuged (2772 $g$ for $10 \mathrm{~min}$ ). The cells were resuspended in $10 \mathrm{ml}$ of $20 \%$ (w/v) peptone (Bacto Proteose Peptone Number 3, Difco) and gently homogenized using a Potter homogenizer operated manually (B. Braun Biotech, Sartorius). The resulting mixture was divided into aliquots and stored at $-70{ }^{\circ} \mathrm{C}$. Frozen inoculum $\left(2 \times 10^{6}\right.$ c.f.u.) was mixed with $80 \mathrm{ml} \mathrm{CDM}$ production medium, containing $0.6 \%(\mathrm{w} / \mathrm{v}$ ) siloxylated polyether EO/PO copolymer Q2-5247 (Dow Corning), and $3 \mathrm{ml}$ of this mixture was placed into each well of the 


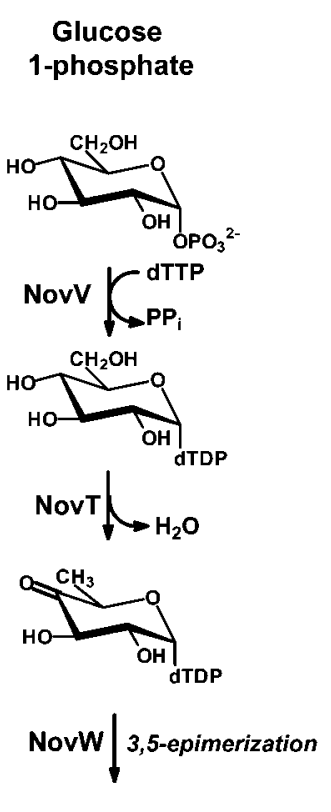

L-Tyrosine Prephenate
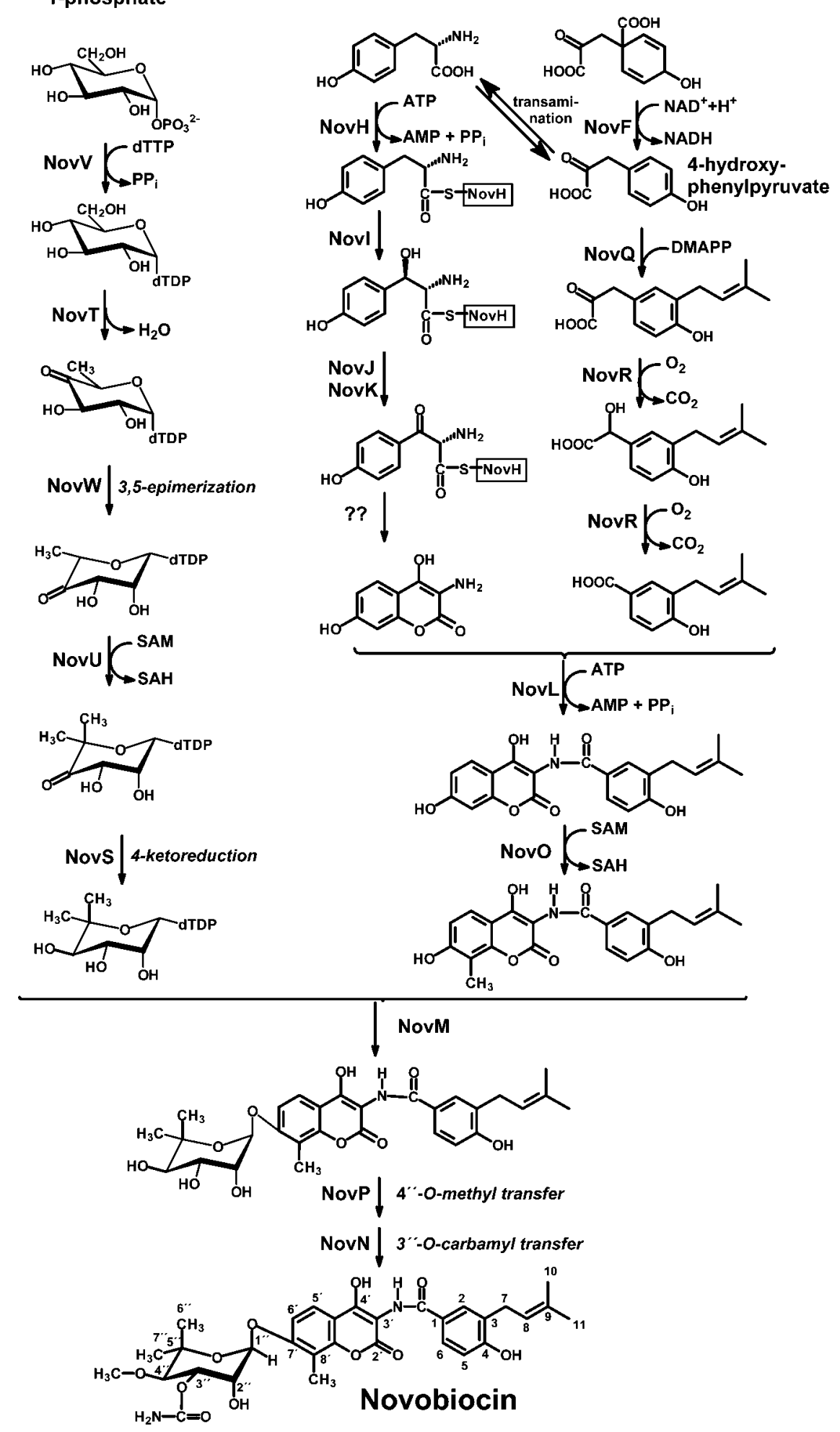

Fig. 1. Functions of the gene products of the 17 genes novF and novHIJKLMNOPQRSTUVW in novobiocin biosynthesis. 
(a)

nov-BG1 (complete cluster)

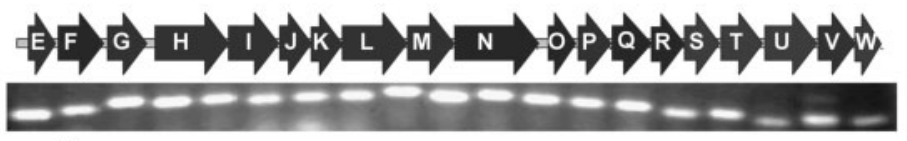

(b)

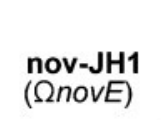

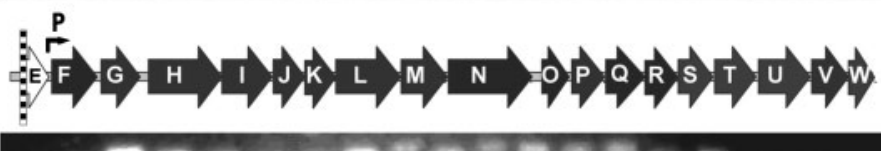

(c) nov-JH2
$(\Omega$ nov $)$
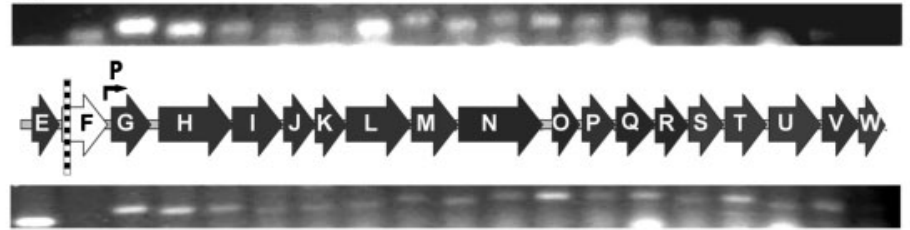

(d)

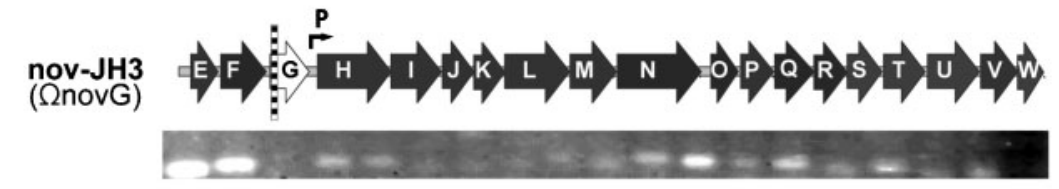

(e)

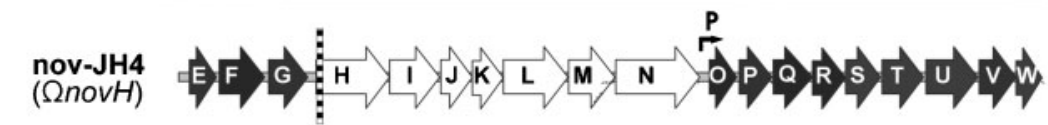

(f)

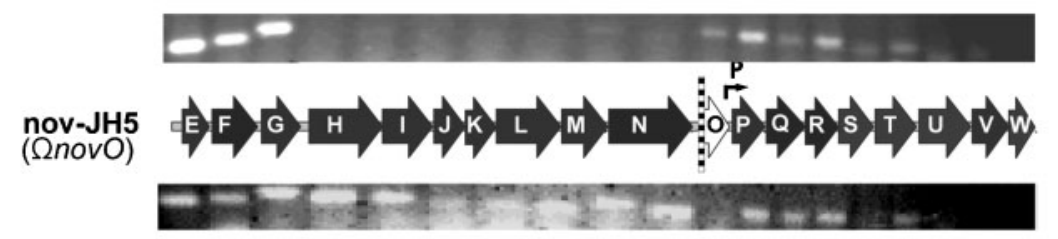

(g)

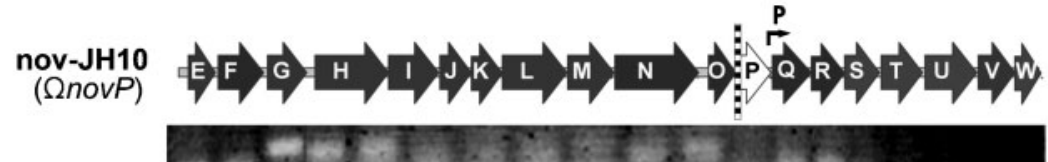

(h)

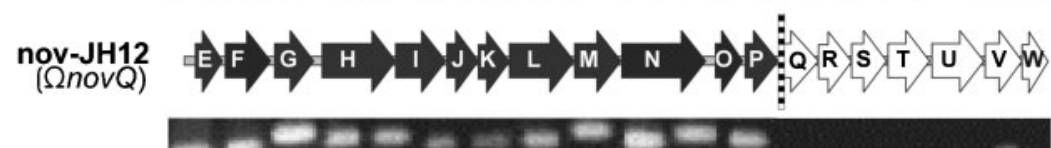

(i)

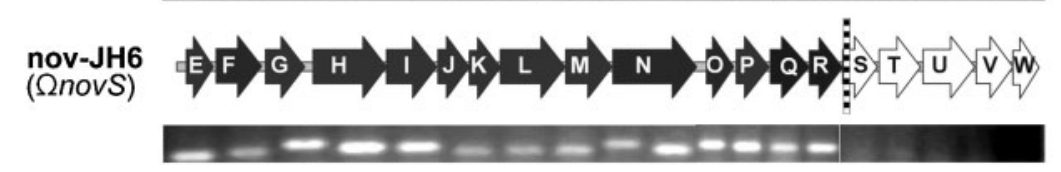

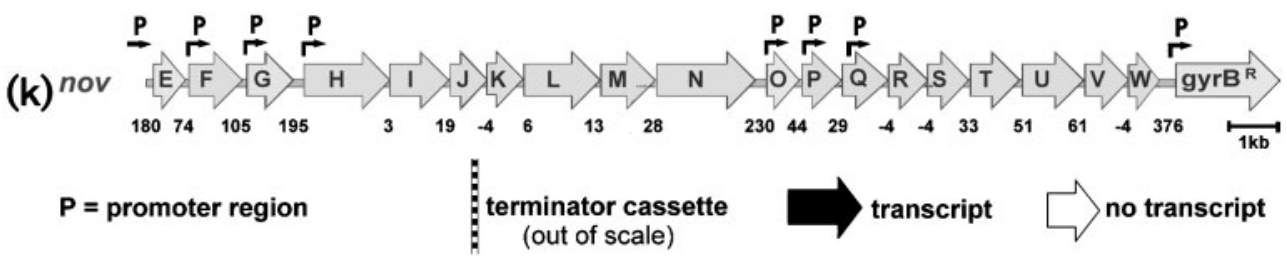

Fig. 2. (a) RT-PCR detection of the transcripts of the novobiocin biosynthetic genes in the heterologous producer strain $S$. coelicolor M512(nov-BG1). (b-i) Insertion of the saac transcriptional terminator cassette into different genes of the novobiocin cluster and RT-PCR analysis of the resulting mutants. ( $k$ ) Location of promoter regions in the novobiocin biosynthetic gene cluster. $g y r B^{R}$, novobiocin resistance gene. Numbers indicate the sizes of the intergenic regions (in bp).

24-square deepwell plates. Cultivation was carried out at $30{ }^{\circ} \mathrm{C}$ and 300 r.p.m.

Kanamycin (for Streptomyces, $15 \mu \mathrm{g} \mathrm{ml}^{-1}$ in liquid medium and $50 \mu \mathrm{g}$ $\mathrm{ml}^{-1}$ in solid medium; for E. coli, $\left.50 \mu \mathrm{g} \mathrm{ml}^{-1}\right)$, chloramphenicol $(25-50 \mu \mathrm{g}$ $\left.\mathrm{ml}^{-1}\right)$, apramycin $\left(50 \mu \mathrm{g} \mathrm{ml}^{-1}\right)$, carbenicillin $\left(50-100 \mu \mathrm{g} \mathrm{ml}^{-1}\right)$ and thiostrepton $\left(8 \mu \mathrm{g} \mathrm{ml}^{-1}\right)$ were used for selection of recombinant strains.

In order to avoid methyl-sensing restriction, the recombinant plasmids and cosmids were amplified in E. coli ET12567 before 
transformation into S. coelicolor strains (MacNeil et al., 1992). The cultivation in production medium was carried out without addition of antibiotics.

DNA isolation, manipulation and cloning. Standard procedures for DNA isolation and manipulation were performed as described by Kieser et al. (2000) and Sambrook \& Russell (2001). Genomic DNA was isolated from $S$. coelicolor strains by using the Kirby mix procedure (Kieser et al., 2000). Southern blot analysis was performed on Hybond-N nylon membranes (Amersham Biosciences) with a digoxigenin-labelled probe by using the DIG High Prime DNA Labelling and Detection Starter kit II (Roche Molecular Biochemicals).

Plasmid construction. For the construction of pAE12, nov $G$ was amplified by PCR using pAE8 as template and the primer pair PG_for (5'-GAA GGT ACG GGA TCC CCA CG-3') and PG_rev (5'-GTC AGG CGG TGT CCC GGT C-3'). The PCR was carried out in a $50 \mu \mathrm{l}$ volume with $100 \mathrm{ng}$ template, $0.2 \mathrm{mM}$ dNTPs, 50 pmol each primer and $5 \%(\mathrm{v} / \mathrm{v})$ DMSO using an Expand High Fidelity PCR system (Roche Molecular Biochemicals): denaturation at $94{ }^{\circ} \mathrm{C}$ for $2 \mathrm{~min}$, then 30 cycles with denaturation at $94{ }^{\circ} \mathrm{C}$ for $45 \mathrm{~s}$, annealing at $57{ }^{\circ} \mathrm{C}$ for $45 \mathrm{~s}$, extension at $72{ }^{\circ} \mathrm{C}$ for $90 \mathrm{~s}$, and a final elongation step at $72{ }^{\circ} \mathrm{C}$ for $5 \mathrm{~min}$. After purification, the PCR product was ligated into pGEM-T to give pAE11. The insert of pAE11 was checked by nucleotide sequencing. The construction of pJH1 and pAE12 is described in Supplementary Table S1. Plasmids were introduced into S. coelicolor M512(nov-BG1) by PEG-mediated protoplast transformation (Kieser et al., 2000).

Insertion of the $\Omega a a c C 4$ terminator cassette into cosmid novBG1 and heterologous expression of the modified cosmids. An apramycin-resistance cassette flanked by transcriptional terminators $(\Omega a a c C 4)$ was used for replacement of the second codon of the genes nove, novF, nov $G, \operatorname{novH}, \operatorname{nov} O, \operatorname{nov} P, \operatorname{nov} Q$ or nov $S$ by $\lambda$ Redmediated recombination (Gust et al., 2003). This resulted in cosmids nov-JH1 to nov-JH6, nov-JH10 and nov-JH12. The cassette for replacement was generated by PCR using the primers listed in Supplementary Table S2. The PCR was performed in a $50 \mu \mathrm{l}$ volume with 50 ng template (pJH1 digested with HinfI and SalI), $0.2 \mathrm{mM}$ dNTPs, 50 pmol each primer and $5 \%(\mathrm{v} / \mathrm{v})$ DMSO, using the Expand High Fidelity PCR system (Roche Molecular Biochemicals): denaturation at $94{ }^{\circ} \mathrm{C}$ for $2 \mathrm{~min}$, then 10 cycles with denaturation at $94{ }^{\circ} \mathrm{C}$ for $45 \mathrm{~s}$, annealing at $50{ }^{\circ} \mathrm{C}$ for $45 \mathrm{~s}$, extension at $72{ }^{\circ} \mathrm{C}$ for $90 \mathrm{~s}$, and then 15 cycles with annealing at $55{ }^{\circ} \mathrm{C}$, and a final elongation step at $72{ }^{\circ} \mathrm{C}$ for 5 min. E. coli XL1 Blue MRF' cells were analysed using restriction enzymes and gel electrophoresis. The generated cosmids were then introduced into $S$. coelicolor M512 by PEG-mediated protoplast transformation (Kieser et al., 2000). Kanamycin- and apramycin-resistant clones were checked for site-specific genomic integration of the cosmids into the $\Phi C 31$ attachment site by Southern blot analysis.

Analysis of secondary metabolites. Analysis of novobiocin production by HPLC was carried out as described previously (Eustáquio et al., 2003).

RNA isolation and purification. For RT-PCR investigations, strains derived from S. coelicolor M512 were cultivated in $300 \mathrm{ml}$ Erlenmeyer flasks as described above. After $72 \mathrm{~h}$ of cultivation the mycelia of $50 \mathrm{ml}$ culture were collected by vacuum filtration.

For qRT-PCR experiments, strains were cultivated in 24-square deepwell plates (Duetz et al., 2000) as described above. After 24, 32, 48, 72 and $96 \mathrm{~h}$ mycelia from four to six wells were pooled and collected by vacuum filtration. After $168 \mathrm{~h}$, only three wells were harvested to analyse final novobiocin production.
Vacuum filtration was followed by rinsing of the cells with $30 \mathrm{ml}$ distilled water. The cells were transferred to a $50 \mathrm{ml}$ Falcon tube containing approximately $14 \mathrm{~g} 3.5-4.5 \mathrm{~mm}$ diameter glass beads and $15 \mathrm{ml}$ modified Kirby mix [1\% (w/v) N-lauroylsarcosine, $6 \%(\mathrm{w} / \mathrm{v})$ sodium salicylate, $6 \%(\mathrm{v} / \mathrm{v})$ phenol (buffered to $\mathrm{pH} 8)$ in $20 \mathrm{mM}$ Tris/ $\mathrm{HCl}(\mathrm{pH} 8.3)]$ and vortexed for $2 \mathrm{~min}$. The cell suspension was sonicated six times for $30 \mathrm{~s}$ with $20 \mathrm{~s}$ intervals (Branson Sonifier 250). To this mixture an equal volume $(15 \mathrm{ml})$ of phenol: chloroform: isoamylalcohol $(25: 24: 1)$ was added, followed by vortexing for $30 \mathrm{~s}$ and centrifugation $\left(5000 \mathrm{~g}\right.$ for $10 \mathrm{~min}$ at $4{ }^{\circ} \mathrm{C}$ ). Clear supernatant was transferred to a clean $50 \mathrm{ml}$ Falcon tube, mixed with an equal volume of 2-propanol and 0.1 volume of $3 \mathrm{M}$ sodium acetate $(\mathrm{pH} 5.2)$, and left for $5 \mathrm{~min}$ at $20{ }^{\circ} \mathrm{C}$. After centrifugation $(5000 \mathrm{~g}$ for $20 \mathrm{~min}$ at $4{ }^{\circ} \mathrm{C}$ ), the supernatant was discarded and the pellet was washed with $2 \mathrm{ml} 70 \%(\mathrm{v} / \mathrm{v})$ ethanol. The pellet was dried and resuspended in $800 \mu \mathrm{l}$ water. After resuspension, a DNase treatment was carried out with DNase I (10 U; Fermentas) according to the manufacturer's instructions using $10 \mathrm{mM}$ Tris/ $\mathrm{HCl}\left(\mathrm{pH} 7.5\right.$ at $25^{\circ} \mathrm{C}$ ), $2.5 \mathrm{mM}$ $\mathrm{MgCl}_{2}, 0.1 \mathrm{mM} \mathrm{CaCl}$ and RNase-free water. Subsequently, RNA was purified with the NucleoSpin RNA Clean-up kit (Macherey \& Nagel) according to the manufacturer's instructions and eluted from the column with $40 \mu \mathrm{l}$ water. RNA was quantified by determination of $A_{280}$. Integrity of RNA was checked by analysing $1 \mu \mathrm{g}$ RNA on a $1.2 \%$ agarose gel.

RT-PCR analysis. The reverse transcriptase reaction was carried out according to the 'Protocol for First Strand cDNA Synthesis' of Fermentas using $5 \mu \mathrm{g}$ total RNA, $0.2 \mu \mathrm{g}$ random hexamer primers, $50 \mathrm{mM}$ Tris/ $\mathrm{HCl}\left(\mathrm{pH} 8.3\right.$ at $25^{\circ} \mathrm{C}$ ), $50 \mathrm{mM} \mathrm{KCl}, 4 \mathrm{mM} \mathrm{MgCl}_{2}$, $10 \mathrm{mM}$ DTT, $20 \mathrm{U}$ RiboLock RNase Inhibitor, dNTPs $(10 \mathrm{mM}$ each), RNase-free water and $200 \mathrm{U}$ RevertAid M-MuLV reverse transcriptase (Fermentas). After the reverse transcriptase reaction, PCRs were carried out using the primers listed in Supplementary Table S2 in a $25 \mu \mathrm{l}$ volume with $1 \mu \mathrm{l}$ template (cDNA from the reverse transcriptase reaction described above), dNTPs $(2.5 \mathrm{mM}$ each), $50 \mathrm{pmol}$ of each primer, $5 \%$ (v/v) DMSO, $10 \mathrm{mM}$ Tris $/ \mathrm{HCl}$ $\left(\mathrm{pH} 8.8\right.$ at $\left.25{ }^{\circ} \mathrm{C}\right), 50 \mathrm{mM} \mathrm{KCl}, 0.08 \%(\mathrm{v} / \mathrm{v})$ Nonidet P40, $1.5 \mathrm{mM}$ $\mathrm{MgCl}_{2}$ and $1 \mathrm{U}$ Taq DNA polymerase: denaturation at $94{ }^{\circ} \mathrm{C}$ for 2 min, 26 cycles with denaturation at $94{ }^{\circ} \mathrm{C}$ for $30 \mathrm{~s}$, annealing at $64.5{ }^{\circ} \mathrm{C}$ (nov $G$ and novs), $60.7{ }^{\circ} \mathrm{C}$ (novF, novH to novK, novO), $58{ }^{\circ} \mathrm{C}$ (novM, novP, novR, novU to novW), $56.2{ }^{\circ} \mathrm{C}(\operatorname{nov} L$, nov $N$, nov $T)$ or $55{ }^{\circ} \mathrm{C}($ novE, nov $\mathrm{Q})$ for $15 \mathrm{~s}$, extension at $72{ }^{\circ} \mathrm{C}$ for $10 \mathrm{~s}$, and a final elongation step at $72{ }^{\circ} \mathrm{C}$ for $7 \mathrm{~min}$. The PCR product was checked by analysing $22 \mu \mathrm{l}$ of the PCR with $8 \mu$ l loading buffer [50\% (v/v) glycerol, $200 \mathrm{mM}$ EDTA, $0.5 \%$ xylene cyanol (Sigma)] on a $1.2 \%$ agarose gel.

qRT-PCR analysis. qRT-PCR was carried out using the LightCycler RNA amplification kit SYBR Green I (Roche). Reaction mixtures were prepared using the primers listed in Supplementary Table S2 and following the manufacturer's instructions; however, the $\mathrm{MgCl}_{2}$ concentration was reduced to $6.25 \mathrm{mM}$ for investigations on novE, novf, novG, novH, nov $O$, novQ and $g y r B^{R}$, and to $12.5 \mathrm{mM}$ for investigations on $h r d B$ and novP. The reverse transcriptase reaction was carried out for $20 \mathrm{~min}$ at $50{ }^{\circ} \mathrm{C}$. Subsequently, the following temperature profile was utilized for amplification: denaturation at $95{ }^{\circ} \mathrm{C}$ for $30 \mathrm{~s}$, followed by 45 cycles at $95{ }^{\circ} \mathrm{C}$ for $1 \mathrm{~s}$ (temperature transition, $\left.20{ }^{\circ} \mathrm{C} \mathrm{s}^{-1}\right), 60$ to $55^{\circ} \mathrm{C}($ novE, novG, novH and novO), 58 to $53{ }^{\circ} \mathrm{C}\left(\mathrm{hrdB}\right.$ and novQ), 56 to $52{ }^{\circ} \mathrm{C}$ (novF, novP and gyrB $B^{R}$ ) (step size, $0.7^{\circ} \mathrm{C}$; step delay, 1 cycle) for $10 \mathrm{~s}$ (temperature transition, $20{ }^{\circ} \mathrm{C} \mathrm{s}^{-1}$ ), and $72{ }^{\circ} \mathrm{C}$ for $13 \mathrm{~s}$ (temperature transition, $2{ }^{\circ} \mathrm{C} \mathrm{s}^{-1}$ ) with stepwise fluorescence acquisition at 60 to $55{ }^{\circ} \mathrm{C}, 58$ to $53{ }^{\circ} \mathrm{C}$ and 56 to $52{ }^{\circ} \mathrm{C}$ in single mode. The number of copies of each sample transcript was then determined with the aid of LightCycler software and normalized to $h r d B$. The specificity of the PCR was verified by agarose gel electrophoresis on $2 \%$ agarose gels. 
EMSAs. The methods used for the EMSAs are described in the supplementary material.

Nucleotide sequence accession numbers (for information). The nucleotide sequences of the genes and DNA regions used in this study are available in the GenBank database under accession numbers AF170880 (novobiocin cluster), AF205854 (novobiocin resistance gene $\left.\operatorname{gyr} B^{R}\right)$ and NC_003888 (hrdB, locus tag SCO5820).

\section{RESULTS}

\section{Insertion of transcriptional terminators and identification of promoter regions by RT-PCR analysis}

A convenient method for the mapping of transcription units is the use of the $\Omega$ (omega) interposon, i.e. a DNA fragment containing an antibiotic resistance marker flanked by short inverted repeats which contain termination signals for transcription and translation (Prentki \& Krisch, 1984; Raynal et al., 2006). Using Red/ET-mediated recombination (Gust et al., 2004), we inserted the $1.8 \mathrm{~kb}$ Saac cassette (Blondelet-Rouault et al., 1997) into the coding sequence of the genes novE, nov, novG, novH, nov $O$ and novS. In each case, the cassette was inserted between nucleotides 3 and 7 of the coding sequence of the gene, i.e. replacing the second codon of the coding sequence. The insertions were carried out using cosmid nov-BG1 as target (Eustáquio et al., 2005a). This cosmid contains the complete novobiocin cluster, as well as the integration functions of the phage $\Phi C 31$. The resulting cosmids with the inserted $\Omega a a c$ cassettes were integrated into the genome of $S$. coelicolor M512 as described previously (Eustáquio et al., 2005a). Southern blotting confirmed that in all integration mutants the entire cosmid had integrated site-specifically into the $\Phi C 31$ attachment site of the genomic DNA (data not shown).

When an S. coelicolor M512 strain carrying the intact novobiocin cluster was cultivated in production medium, RT-PCR experiments revealed the presence of transcripts for all genes of the novobiocin gene cluster (Fig. 2a). Controls without the reverse transcriptase confirmed that the detected signals were not due to contamination with genomic DNA.

Insertion of the $\Omega a a c$ cassette into a transcription unit leads to termination of mRNA synthesis at the site of insertion. Transcription is reinitiated at the next active promoter sequence downstream of the $\Omega a a c$ insertion site. As shown in Fig. 2(b, c and d), insertion of the $\Omega a a c$ cassette into the second codon of novE, nov $F$ and $n o v G$ led, as expected, to a complete abolition of the transcription of the affected genes themselves. In all three cases, however, transcripts of the adjacent gene, i.e. novF, nov $G$ and novH, respectively, were detectable, indicating the presence of promoter regions upstream of the latter genes. In contrast, insertion of $\Omega a a c$ into novH led to a complete abolition of the transcription of novHIJKLMN, indicating that all of these genes are part of a single transcription unit (Fig. 2e). Transcripts were detected, however, for nov $O$ and the genes downstream thereof, indicating the presence of a promoter region upstream of novO.

This finding prompted us to generate three additional mutant strains, carrying $\Omega a a c$ insertions in novO, novP and $n o v Q$. In the first two cases, transcripts of the adjacent genes, i.e. novP and novQ, were detected (Fig. 2f, g), indicating that promoter sequences are located upstream of these genes. As shown by the subsequent qRT-PCR experiments (see below), only small amounts of transcripts are generated from the promoters upstream of novO, novP and novQ. Therefore, only weak bands are seen for most genes downstream of novQ, and transcripts of novUVW are below the detection limit. In the strain with the $\Omega a a c$ insertion in $n o v Q$, transcription of the following genes was completely abolished, indicating that nov $Q$ forms a transcription unit with these genes (Fig. 2h). This was confirmed by the insertion of $\Omega$ aac into novS, resulting in a complete abolition of the transcription of novSTUVW (Fig. 2i).

Therefore, our experiments showed that promoter regions are located upstream of novF, nov $G$, novH, nov $O$, novP and $n o v Q$. Experimental evidence for the promoter activity of the DNA regions upstream of $n o v E$ and $g y r B^{R}$ has been published previously (Dangel et al., 2008; Thiara \& Cundliffe, 1989). Therefore, it can be concluded that at least eight DNA regions with promoter activity are present within the novobiocin cluster (Fig. 2k).

Fig. 2(h) appears to show a small amount of transcript for nov $V$. However, we do not suggest that an additional promoter is present upstream of novV, as this band was only visible in this single experiment and not others, e.g. in Fig. 2(i).

\section{The $\mathbf{1 6}$ genes from novH to novW are transcribed predominantly as a single polycistronic mRNA}

Insertion of the $\Omega a a c$ cassette into novH led to the complete termination of the transcription of novHIJKLMN (see above). Consistently, the strain carrying this insertion (hereafter called strain $\Omega$ novH) did not produce any detectable amounts of novobiocin $\left(<0.2 \mathrm{mg} \mathrm{l}^{-1}\right)$, while a strain carrying the intact cluster produced $51 \mathrm{mg}$ novobiocin $1^{-1}$. The genes nov $Q R$, situated further downstream of novH, direct the biosynthesis of the prenylated 4hydroxybenzoate moiety, also referred to as 'ring A' of novobiocin (Pojer et al., 2003a, b). If novQ and novR were well expressed in the $\Omega$ novH strain, we would expect an accumulation of the ring A moiety (see Fig. 1). However, the $\Omega$ novH strain accumulated only marginal amounts of ring A $\left(<0.3 \mathrm{mg} \mathrm{l}^{-1}\right)$. This suggested that in the $\Omega$ novH strain, nov $Q$ and novR are only transcribed to a low extent. We confirmed this speculation by qRT-PCR experiments, comparing the numbers of transcripts of nov $G$, novH, novP and novQ in S. coelicolor M512(nov-BG1), carrying the intact cluster, with those in S. coelicolor M512(nov-JH4), 
carrying the $\Omega$ novH cluster. In the latter strain the number of transcripts of novH was reduced to $<1 \%$ in comparison with the former strain, but also the transcripts of novP and novQ were reduced to $3 \%$ in comparison with the former strain (Supplementary Fig. S1). This can be explained by the hypothesis that transcription of novO, novP and nov $Q$ (and of the genes located downstream thereof) is mainly controlled by the promoter located upstream of novH, which initiates a large transcript containing all 16 genes from $n o v H$ to $n o v W$, while the promoter regions upstream of nov $\mathrm{n}$ novP and nov $\mathrm{Q}$ have only minor relevance to the amounts of transcripts formed.

\section{qRT-PCR investigations of the influence of novE and novG on the transcription of the novobiocin biosynthetic gene cluster}

In order to investigate the influence of novE and novG on the transcription of the genes within the novobiocin cluster, we carried out qRT-PCR experiments. Suitable primer pairs were chosen for each of the eight genes located downstream of putative promoter sequences within the novobiocin cluster, i.e. novE, novF, novG, novH, novO, $n o v P$, nov $Q$ and $\operatorname{gyr} B^{R}$. Reaction conditions, i.e. annealing temperature and $\mathrm{MgCl}_{2}$ concentrations, were optimized for each primer pair until a linear relationship between the logarithm of the mRNA concentration and the cycle number was obtained over a concentration range of at least two orders of magnitude. The $h r d B$ transcript, encoding the principal sigma factor of $S$. coelicolor, was used as an internal standard, and the number of transcripts for each sample was normalized to $h r d B$.

qRT-PCR analysis was then carried out, comparing the number of transcripts in three different strains. One strain carried the intact novobiocin cluster, and the two other strains carried clusters in which either novE or novG had been inactivated by an in-frame deletion (Dangel et al., 2008; Eustáquio et al., 2005b).

We first determined the time-course of novobiocin production (Fig. 3a). Only traces of novobiocin were detected within the first $48 \mathrm{~h}$ after inoculation, while the highest novobiocin production rate was observed between 72 and $96 \mathrm{~h}$ after inoculation. In contrast, dry cell weight increased between 24 and $72 \mathrm{~h}$ after inoculation (Siebenberg et al., 2009), confirming the earlier observation that novobiocin production starts at the transition from growth phase to stationary phase (Kominek, 1972).

As may be expected, the highest amounts of transcripts for the novobiocin biosynthetic genes novH, novO, novP and nov $\mathrm{Q}$ were detected immediately before the onset of novobiocin production, i.e. $48 \mathrm{~h}$ after inoculation (Fig. $3 \mathrm{e}-\mathrm{h})$. Thereafter, the amount of transcripts decreased, but they were still clearly detectable after 72 and 96 h, i.e. in the early stationary phase. Expression of all four genes was perfectly synchronous, which is in accordance with the hypothesis that all these genes are transcribed as a single operon. During the active growth phase, i.e. $32 \mathrm{~h}$ after inoculation, hardly any transcripts were found for these four genes.

In contrast, transcripts for the two putative regulators novE and novg could clearly be detected at $32 \mathrm{~h}$ after inoculation, indicating that the expression of the regulatory genes (especially novE) is initiated earlier than the expression of the biosynthetic enzymes (Fig. 3b, d).

For the resistance gene $g y r B^{R}$, a first maximum of transcripts was detected after $48 \mathrm{~h}$, i.e. synchronous with the expression of novH and novOPQ. It is tempting to speculate that this may be caused by co-transcription of gyrB $B^{R}$ with the genes from novH to novW on a single mRNA. In sharp contrast to novH and novOPQ, however, the amount of transcripts for $g y r B^{R}$ increased again after $72 \mathrm{~h}$, i.e. at the time when novobiocin concentration started to rise. This is in accordance with the results of Thiara \& Cundliffe (1989), who cloned the promoter region of $g y r B^{R}$ into a promoter probe vector and showed (by expression in Streptomyces lividans TK24) that the promoter was induced by cultivation in the presence of novobiocin. Thiara \& Cundliffe suggested that this induction is mediated by the change of superhelical density of chromosomal DNA (i.e. loss of negative supercoils), caused by the gyrase inhibitor novobiocin.

In contrast to the strain with the intact cluster, the two strains with in-frame deletions in the putative regulators novE and novG showed only marginal novobiocin production (Fig. 3a). Seven days after inoculation, the strain with the intact cluster had accumulated $45 \mathrm{mg}$ novobiocin $\mathrm{l}^{-1}$ in this experiment, whereas the $\Delta n o v E$ and $\Delta$ nov $G$ strains had produced less than $0.4 \mathrm{mg} \mathrm{l}^{-1}$. The amounts of transcripts for the novobiocin biosynthetic genes novH and novOPQ were dramatically reduced in the $\Delta n o v E$ and $\Delta n o v G$ strains in comparison with the strain with the intact cluster (Fig. 3e-h), proving that novE and nov $G$ act as transcriptional regulators in novobiocin biosynthesis. Notably, novG transcription was also strongly reduced in the $\Delta$ novE strain: at $48 \mathrm{~h}$ after inoculation, the amount of transcript was only $5 \%$ of that observed in the strain with the intact cluster (Fig. 3d). This suggests that nov $G$ expression is largely, though not entirely, dependent on the presence of novE. In contrast, novE expression was still quite high in the $\Delta$ nov $G$ strain (Fig. 3b), suggesting that novE expression is not dependent on novG.

The predicted gene product of novF shows high sequence similarity to prephenate dehydrogenases and is therefore expected to supply 4HPP, the common precursor of both the prenylated 4-hydroxybenzoate moiety and the aminocoumarin moiety of novobiocin (Fig. 1). Transcription of $n o v F$ is remarkably similar to that of novE in the strain with the intact cluster and in the $\Delta \operatorname{nov} G$ strain (Fig. 3c), which indicates either close co-regulation or even co-transcription of both genes. 
S. coelicolor(nov-BG1) (complete cluster)
S. coelicolor(nov-VD2) (novE-defective cluster)
S. coelicolor(nov-AE12) (novG-defective cluster)

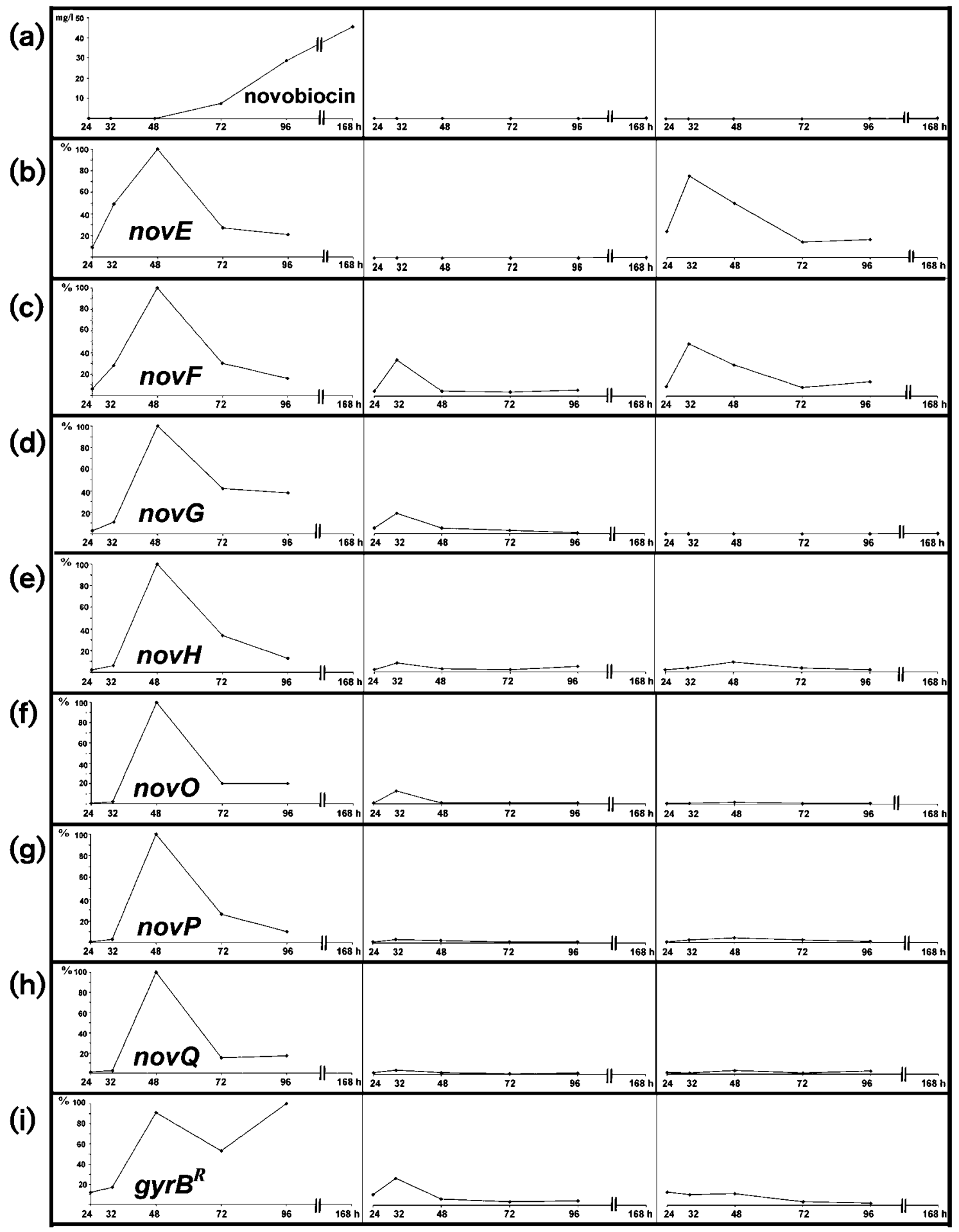

Fig. 3. $q R T-P C R$ analysis of $S$. coelicolor M512(nov-BG1) containing the entire novobiocin biosynthetic gene cluster, $S$. coelicolor M512(nov-VD2) containing the novE-defective cluster and S. coelicolor M512(nov-AE10) containing the novGdefective cluster. (a) Production of novobiocin. (b-i) qRT-PCR analysis of the expression of selected genes of the novobiocin biosynthetic gene cluster. 


\section{Construction of an optimized novG expression vector for novobiocin overproduction}

The results described above suggest that control of transcription from the promoter upstream of novH is the central mechanism for regulation of novobiocin biosynthesis. We tried to utilize this knowledge in order to increase novobiocin yields.

Transcription from the promoter upstream of novH is positively regulated by the DNA-binding protein NovG. The NovG binding site has been identified in the intergenic region between novG and novH. The palindromic sequence of this binding site (Fig. 4a) begins 2 bp downstream of the nov $G$ stop codon, i.e. 194 bp upstream of the novH start codon (Fig. 4a).

Using a previously constructed nov $G$ expression vector, pAE8 (Eustáquio et al., 2005b), we could increase novobiocin production in the heterologous novobiocin production strain 2.9-fold in comparison with the empty vector control. However, pAE8 contained not only the coding sequence of nov $G$ but also $135 \mathrm{bp}$ of the intergenic region downstream of $\operatorname{nov} G$, i.e. it included the NovG binding site (Fig. 4b). We speculated that this was not an optimal construct to increase novobiocin production, since much of the translated NovG protein would bind to the NovG binding site in the multicopy plasmid pAE8, leaving only a fraction of the produced NovG available for binding within the novobiocin cluster. Therefore, we constructed a new nov $G$ expression plasmid, named pAE12, which contained just $1 \mathrm{bp}$ of the intergenic region downstream of $n o v G$, and therefore did not contain the NovG binding site (Fig. 4c). Otherwise, this plasmid was identical to pAE8. Transformation of this plasmid into a heterologous expression strain carrying the intact novobiocin cluster resulted in 8.4-fold overproduction of novobiocin compared with the empty vector control. This is the most effective genetic method for the stimulation of novobiocin production identified so far.

(a)

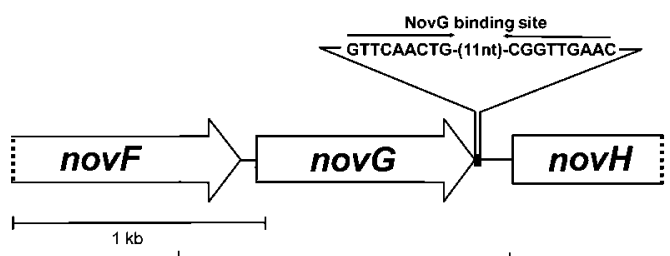

(b)

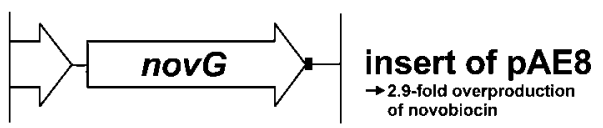

(c)

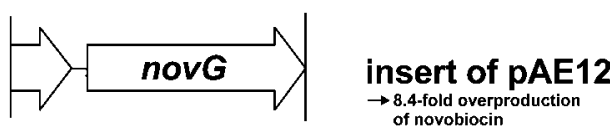

Fig. 4. (a) Schematic representation of the regulator gene novG and the binding site of its gene product. $(b, c)$ Inserts of the nov $G$ overexpression plasmids PAE8 and PAE12.

\section{DISCUSSION}

The present study provides evidence for the role of novE and nov $G$ in the transcriptional regulation of novobiocin biosynthesis.

qRT-PCR experiments showed that effective transcription from the promoter upstream of novH depends on the presence of novG (Fig. 3). Transcription from this promoter may result in a large polycistronic mRNA containing all 16 genes from novH to novW which together direct all steps of novobiocin biosynthesis from glucose 1-phosphate and 4-HPP or tyrosine (Fig. 1). Possibly, even the resistance gene $g y r B^{R}$ is included in this transcript, extending it to a size of $20 \mathrm{~kb}$. Transcripts of this size are not unusual in secondary metabolic gene clusters, as the coding sequences of modular polyketide synthase or nonribosomal peptide synthase genes often span even larger DNA regions (Fischbach \& Walsh, 2006).

Within the suggested large operon starting with novH, RTPCR had indicated the presence of internal promoters upstream of nov $O$, novP and novQ. Internal promoters within operons have been identified previously in Streptomyces, e.g. galP2, a low-level constitutive promoter internal to the galactose operon in S. lividans and $S$. coelicolor A3(2) (Westpheling \& Brawner, 1989). A recent study (Laing et al., 2006) suggests that in S. coelicolor (in contrast to E. coli and Bacillus subtilis), expression levels of the individual genes of an operon decrease with increasing distance from the transcription start, and suggests that the frequently encountered internal promoters ensure adequate transcription of the terminal genes of an operon. Under our experimental conditions, however, transcription from the internal promoters upstream of novO, novP and nov $Q$ was low in the $\Omega$ novH strain, and these promoters may not have a significant role in novobiocin biosynthesis.

For the first time, to our knowledge, our study shows that effective transcription of nov $G$ depends on the presence of novE (Fig. 3d). This suggests a cascade-like regulation mechanism of novE and novG, i.e. novE triggers transcription of nov $G$, which in turn triggers transcription of the novobiocin biosynthetic genes. Consistent with this hypothesis, novobiocin formation in a novE-defective mutant could be restored by an intact copy of novG, while novobiocin formation in a novG-defective mutant remained low even after expression of novE (Dangel et al., 2008).

While we could prove that novE positively regulates transcription of novG, the precise mechanism of this regulation is as yet unknown. We could not demonstrate binding of the NovE protein to the DNA region upstream of novG (Dangel et al., 2008). Further proteins may be involved in the regulation by NovE. Also, the mechanism which controls transcription of novE is unknown. It should be noted, however, that novE contains a TTA codon, which is rare in Streptomyces. Expression of novE therefore depends on the expression of the gene for the UUA-specific 
tRNA bldA, which appears to be involved in the regulation of secondary metabolism in streptomycetes (Chandra \& Chater, 2008).

Notably, our RT-PCR results did not allow us to distinguish between low and high expression of the biosynthetic genes. Only the subsequent qRT-PCR revealed a correct picture of the amount of transcripts of the genes of novobiocin biosynthesis.

All experiments in the present study were carried out in a heterologous producer strain, which carries the novobiocin gene cluster integrated into the $\Phi C 31$ attachment site of the chromosome. As described for the genuine producer strain (Kominek, 1972), novobiocin production in the heterologous producer strain started at the transition from the growth phase to the stationary phase, suggesting that novE and nov $G$ expression was regulated in a similar timely fashion as in the genuine novobiocin producer strain. The mechanism that triggers expression of novE and novG remains to be elucidated for both strains.

\section{ACKNOWLEDGEMENTS}

We thank Alessandra Eustáquio for the construction of pAE12, Katrin Flinspach, Marc Burian and Vittoria Bisanzio for their help in qRTPCR experiments, and Tilmann Weber for help in the bioinformatic analysis of the novobiocin biosynthetic gene cluster. This work was supported by grants from the European Commission (IP 005224 ActinoGEN) and from the Deutsche Forschungsgemeinschaft (SFB766).

\section{REFERENCES}

Blondelet-Rouault, M. H., Weiser, J., Lebrihi, A., Branny, P. \& Pernodet, J. L. (1997). Antibiotic resistance gene cassettes derived from the $\Omega$ interposon for use in E. coli and Streptomyces. Gene 190, 315-317.

Chandra, G. \& Chater, K. F. (2008). Evolutionary flux of potentially bldA-dependent Streptomyces genes containing the rare leucine codon TTA. Antonie Van Leeuwenhoek 94, 111-126.

Dangel, V., Eustáquio, A. S., Gust, B. \& Heide, L. (2008). novE and nov $G$ act as positive regulators of novobiocin biosynthesis. Arch Microbiol 190, 509-519.

Duetz, W. A., Rüedi, L., Hermann, R., O’Connor, K., Büchs, J. \& Witholt, B. (2000). Methods for intense aeration, growth, storage, and replication of bacterial strains in microtiter plates. Appl Environ Microbiol 66, 2641-2646.

Eustáquio, A. S., Luft, T., Wang, Z. X., Gust, B., Chater, K. F., Li, S. M. \& Heide, L. (2003). Novobiocin biosynthesis: inactivation of the putative regulatory gene novE and heterologous expression of genes involved in aminocoumarin ring formation. Arch Microbiol 180, 25-32.

Eustáquio, A. S., Gust, B., Galm, U., Li, S. M., Chater, K. F. \& Heide, L. (2005a). Heterologous expression of novobiocin and clorobiocin biosynthetic gene clusters. Appl Environ Microbiol 71, 2452-2459.

Eustáquio, A. S., Li, S. M. \& Heide, L. (2005b). NovG, a DNA-binding protein acting as a positive regulator of novobiocin biosynthesis. Microbiology 151, 1949-1961.

Fischbach, M. A. \& Walsh, C. T. (2006). Assembly-line enzymology for polyketide and nonribosomal peptide antibiotics: logic, machinery, and mechanisms. Chem Rev 106, 3468-3496.
Gust, B., Challis, G. L., Fowler, K., Kieser, T. \& Chater, K. F. (2003). PCR-targeted Streptomyces gene replacement identifies a protein domain needed for biosynthesis of the sesquiterpene soil odor geosmin. Proc Natl Acad Sci US A 100, 1541-1546.

Gust, B., Chandra, G., Jakimowicz, D., Yuqing, T., Bruton, C. J. \& Chater, K. F. (2004). $\lambda$ Red-mediated genetic manipulation of antibiotic-producing Streptomyces. Adv Appl Microbiol 54, 107-128.

Heide, L., Gust, B., Anderle, C. \& Li, S. M. (2008). Combinatorial biosynthesis, metabolic engineering and mutasynthesis for the generation of new aminocoumarin antibiotics. Curr Top Med Chem 8, 667-679.

Kieser, T., Bibb, M. J., Buttner, M. J., Chater, K. F. \& Hopwood, D. A. (2000). Practical Streptomyces Genetics. Norwich, UK: John Innes Foundation.

Kominek, L. A. (1972). Biosynthesis of novobiocin by Streptomyces niveus. Antimicrob Agents Chemother 1, 123-134.

Laing, E., Mersinias, V., Smith, C. P. \& Hubbard, S. J. (2006). Analysis of gene expression in operons of Streptomyces coelicolor. Genome Biol 7, R46.

Li, S. M. \& Heide, L. (2004). Functional analysis of biosynthetic genes of aminocoumarins and production of hybrid antibiotics. Curr Med Chem Anti-Infect Agents 3, 279-295.

Li, S. M. \& Heide, L. (2005). New aminocoumarin antibiotics from genetically engineered Streptomyces strains. Curr Med Chem 12, 419427.

Li, S. M. \& Heide, L. (2006). The biosynthetic gene clusters of aminocoumarin antibiotics. Planta Med 72, 1093-1099.

MacNeil, D. J., Gewain, K. M., Ruby, C. L., Dezeny, G., Gibbons, P. H. \& MacNeil, T. (1992). Analysis of Streptomyces avermitilis genes required for avermectin biosynthesis utilizing a novel integration vector. Gene 111, 61-68.

Maxwell, A. \& Lawson, D. M. (2003). The ATP-binding site of type II topoisomerases as a target for antibacterial drugs. Curr Top Med Chem 3, 283-303.

Pojer, F., Kahlich, R., Kammerer, B., Li, S. M. \& Heide, L. (2003a). CloR, a bifunctional non-heme iron oxygenase involved in clorobiocin biosynthesis. J Biol Chem 278, 30661-30668.

Pojer, F., Wemakor, E., Kammerer, B., Chen, H., Walsh, C. T., Li, S. M. \& Heide, L. (2003b). CloQ, a prenyltransferase involved in clorobiocin biosynthesis. Proc Natl Acad Sci U S A 100, 2316-2321.

Prentki, P. \& Krisch, H. M. (1984). In vitro insertional mutagenesis with a selectable DNA fragment. Gene 29, 303-313.

Raynal, A., Karray, F., Tuphile, K., Darbon-Rongere, E. \& Pernodet, J. L. (2006). Excisable cassettes: new tools for functional analysis of Streptomyces genomes. Appl Environ Microbiol 72, 4839-4844.

Sambrook, J. \& Russell, D. W. (2001). Molecular Cloning: a Laboratory Manual, 3rd edn. Cold Spring Harbor, NY: Cold Spring Harbor Laboratory.

Shawky, R. M., Puk, O., Wietzorrek, A., Pelzer, S., Takano, E., Wohlleben, W. \& Stegmann, E. (2007). The border sequence of the balhimycin biosynthesis gene cluster from Amycolatopsis balhimycina contains $b b r$, encoding a StrR-like pathway-specific regulator. J Mol Microbiol Biotechnol 13, 76-88.

Siebenberg, S., Bapat, P. M., Lantz, A. E., Gust, B. \& Heide, L. (2009). Reducing the variability of antibiotic production in Streptomyces by cultivation in 24-square deepwell plates. J Biosci Bioeng (in press).

Thiara, A. S. \& Cundliffe, E. (1989). Interplay of novobiocin-resistant and -sensitive DNA gyrase activities in self-protection of the novobiocin producer, Streptomyces sphaeroides. Gene 81, 65-72. 
Tomono, A., Tsai, Y., Yamazaki, H., Ohnishi, Y. \& Horinouchi, S. (2005). Transcriptional control by A-factor of $s t r R$, the pathwayspecific transcriptional activator for streptomycin biosynthesis in Streptomyces griseus. J Bacteriol 187, 5595-5604.

Westpheling, J. \& Brawner, M. (1989). Two transcribing activities are involved in expression of the Streptomyces galactose operon. J Bacteriol 171, 1355-1361.
Wilkinson, B. \& Micklefield, J. (2007). Mining and engineering natural-product biosynthetic pathways. Nat Chem Biol 3, 379-386.

Zerikly, M. \& Challis, G. L. (2009). Strategies for the discovery of new natural products by genome mining. ChemBioChem 10, 625633.

Edited by: C. W. Chen 